University of Texas Rio Grande Valley

ScholarWorks @ UTRGV

Psychological Science Faculty Publications and Presentations

$10-2017$

\title{
Assessing the factor structure of the Childhood Trauma Questionnaire, and cumulative effect of abuse and neglect on mental health among adolescents in conflict-affected Burundi
}

\author{
Ruby Charak \\ The University of Texas Rio Grande Valley, ruby.charak@utrgv.edu \\ JTVM de Jong \\ University of Amsterdam \\ Lidewyde H. Berckmoes \\ Netherlands Institute for the Study of Crime and Law Enforcement \\ Herman Ndayisaba \\ Transcultural Pscyhosocial Organisation \\ Ria Reis \\ Leiden University \\ Follow this and additional works at: https://scholarworks.utrgv.edu/psy_fac \\ Part of the Child Psychology Commons
}

\section{Recommended Citation}

Charak, R., de Jong, J.T.V.M., Berckmoes, L. H., Ndayisaba, H., \& Reis, R. (2017). Assessing the factor structure of the childhood trauma questionnaire, and cumulative effects of abuse and neglect on mental health among adolescents in conflict-affected Burundi. Child Abuse and Neglect, 72, 383-392.

doi.10.1016/j.chiabu.2017.09.009

This Article is brought to you for free and open access by the College of Liberal Arts at ScholarWorks @ UTRGV. It has been accepted for inclusion in Psychological Science Faculty Publications and Presentations by an authorized administrator of ScholarWorks @ UTRGV. For more information, please contact justin.white@utrgv.edu, william.flores01@utrgv.edu. 
APA Citation.

Charak, R., de Jong, J.T.V.M., Berckmoes, L. H., Ndayisaba, H., \& Reis, R. (2017). Assessing the factor structure of the childhood trauma questionnaire, and cumulative effects of abuse and neglect on mental health among adolescents in conflict-affected Burundi. Child Abuse and Neglect, 72, 383-392. doi.10.1016/j.chiabu.2017.09.009

Note. The following document is the final version of the accepted manuscript (Post peerreview; before the proof-reading stage). It may differ from the published article. 


\title{
Assessing the Factor Structure of the Childhood Trauma Questionnaire, and \\ Cumulative Effect of Abuse and Neglect on Mental Health among Adolescents in Conflict-affected Burundi
}

\author{
Ruby Charak \\ Department of Psychological Science, The University of Texas Rio Grande Valley, \\ U.S.A \\ JTVM de Jong \\ Amsterdam Institute for Social Science, University of Amsterdam; Boston University \\ School of Medicine, U.S.A. \\ Lidewyde H. Berckmoes \\ Netherlands Institute for the Study of Crime and Law Enforcement, The Netherlands \\ Herman Ndayisaba \\ Transcultural Psychosocial Organisation, Burundi \\ Ria Reis \\ Leiden University Medical Center, Leiden University, the Netherlands; Amsterdam \\ Institute for Social Science Research, University of Amsterdam, The Netherlands; The \\ Children's Institute, University of Cape Town, South Africa
}

Corresponding author: Ruby Charak, Ph.D., Assistant Professor, Department of Psychological Science, The University of Texas Rio Grande Valley, Edinburg, Texas 78539. Email: ruby.charak@utrgv.edu Tel: +1-(956)6653733. Fax: +1-(956)6653333 
Funding: This work was supported by The Government of the Netherlands, through the UNICEF Peacebuilding, Education and Advocacy Program in Burundi, and in part by the National Science Foundation (under grant HRD-1463991). Any opinions, findings, and conclusions or recommendations are those of the authors, and do not necessarily reflect the view of the grant agencies.

Acknowledgements: We thank Dr. P. Verwimp and Dr. Hans M. Koot for their help in sampling of data and in procuring the measures, respectively. We would also like to thank all interviewers who helped with the data collection. Special thanks to all participants for their time and participation. 


\begin{abstract}
The present study aimed to examine the factor structure of the Childhood Trauma Questionnaire (CTQ; Bernstein \& Fink, 1998), highlight rates of abuse and neglect among Burundian adolescents, compare these rates with those found in high-income nations, and examine the cumulative effect of multiple types of abuse and neglect on depression and PTSD symptoms. Participants were 231 adolescents and youth $(M=14.9$, $S D=1.99,58.4 \%$ female) from five provinces of Burundi, a country in Central Africa affected by war and political violence. Translation and back-translation of the CTQ was carried out to obtain an adaptation of CTQ in Kirundi, the native language of Burundi. With the exception of one item on 'molestation' in the factor of sexual abuse, the fivefactor structure of CTQ was obtained comprising latent factors, namely emotional, physical, and sexual abuse, and emotional and physical neglect. The rate of abuse and neglect ranged from $14.7-93.5 \%$ with more than $37 \%$ reporting 4 or more types of abuse and neglect experiences. Emotional abuse and neglect, and physical neglect were 2-3 times higher among Burundian adolescents when compared with studies from highincome countries using the CTQ. A cumulative effect of multiple types of abuse and neglect was found, such that, those with 4 or more types of maltreatment were higher on symptoms of depression and posttraumatic stress. Findings highlight the need for culturally sensitive, standardized, and validated measures and norms for gauging childhood maltreatment in Burundi and related need for preventative interventions on childhood maltreatment.
\end{abstract}

Keywords: Child Abuse and Neglect, CTQ, Burundi, Africa, Cumulative risk, Low Income Country 


\section{Assessing the Factor Structure of the Childhood Trauma Questionnaire, and the Cumulative Effect of Abuse and Neglect on Mental Health among Adolescents in Conflict-affected Burundi}

Child abuse and neglect are major global public health issues, with exposure to maltreatment being associated with increase in internalizing and externalizing psychopathology among children and adolescents (Arata, Langhinrichsen-Rohling, Bowers, \& O’Brien, 2007; Charak \& Koot, 2015; Petrenko, Friend, Garrido, Taussig, \& Culhane, 2012). However, a large portion of the research on child maltreatment is based on samples from high-income nations, while the risk factors associated with child abuse and neglect are higher in low-and middle-income countries, including most African nations. To name a few, these risk factors include poverty (Youssef, Attia, \& Kamel, 1998), low literacy rates (Meinck, Cluver, Boyes, \& Ndhlovu, 2015), lack of legislation and child welfare services, poor access to health and education services (World Health Organization [WHO], 2011), and residing in conflict zones (Catani, Jacob, Schauer, Kohila, \& Neuner, 2008; for a review see Meinck et al., 2015).

Burundi, a small landlocked country located in the Central African Great Lakes region, is one such nation confronted with many risk factors mentioned previously. Burundi's population is one of the poorest in the world with more than $64 \%$ living below the poverty line (based on data from 2014, World Bank 2016) and 80\% experience multidimensional poverty, that is, deprivation in areas of health, education, and standard of living (Oxford Poverty and Human Development Initiative, 2016). The majority of the population lives on subsistence farming, and pressure on the land is high as Burundi is 
the third most densely populated country in Africa with a high annual population growth rate of 3.3\% (based on data from 2014, World Bank 2016). Burundi's poverty stems partly from the long history of violent conflicts (e.g., Verwimp \& Bundervoet, 2009) since its independence in 1962. In 2005, Burundi emerged from a 12-year civil war, and in its aftermath, the country continued to struggle with poverty, corruption and impunity and a legacy of ethnic, regional, and political divisions (cf. Berckmoes, 2014, 2015). Violent political contestations were on the rise again after the 2010 elections (e.g. Human Rights Watch, 2010), with political violence reaching a new peak in the electoral period in 2015, a month after data collection for this study took place. Since then, more than 300,000 refugees have fled the country (UNHCR, 2016). At least 400 people have been killed and thousands have been arrested and possibly subjected to human rights violations (UN, 2016).

\section{Child Abuse and Neglect in Africa}

Research on child abuse and neglect in Africa generally, and specifically in Burundi is extremely limited. Most studies available from Sub-Saharan Africa report on findings from South Africa. To the best of our knowledge, only two studies examined childhood maltreatment in the context of Burundi, one focusing on street children and the second limited to two urban neighbourhoods in Burundi's capital (Crombach et al., 2014; Crombach \& Bambonyé, 2015). Overall, studies from Africa report elevated rates of child abuse, as high as 53\% for physical abuse and 56\% for sexual abuse (Meinck et al 2015). Presence of risk factors, such as, war, high levels of poverty, high prevalence of infectious disease, including HIV, and different family structures and socio-cultural attitudes, suggest that child abuse and neglect in low-and-middle income countries in 
Africa occur in higher rates compared to high-income countries (Laird, 2016; Meinck et al. 2015). However, comparative studies of child maltreatment across nations is challenging as prior research studies vary greatly in terms of definitions of child abuse and neglect, nature of the study sample, recruitment, scales/instruments used, procedures followed, and due to diverse cultural/or socio-cultural contexts (Meinck et al., 2015; Nichols et al., 2013; Stoltenborgh et al. 2013). To overcome current limitations for crosscultural comparison and to allow for more context-sensitive knowledge, empirical research based on validated and standardized measures of child abuse and neglect in Burundi and other African countries, is urgently needed.

\section{Factor Analytic Studies of the Childhood Trauma Questionnaire from Around the}

\section{World}

A popular and standardized measure for assessing childhood maltreatment is the Childhood Trauma Questionnaire (CTQ; Bernstein \& Fink, 1998), which was also used in the present study. Based on factor analytic studies the original five-factors structure comprising emotional abuse, physical abuse, sexual abuse, emotional neglect, and physical neglect has been supported across diverse populations (e.g., adolescents, substance users, sex workers; Bernstein et al., 2003; Bogaerts, Daalder, Spreen, van der Knaap, \& Henrichs, 2011; Forde, Baron, Scher, \& Stein, 2012) and across nations (e.g., the U.S., Canada, Bernstein et al., 2003; Paivio \& Cramer, 2004). However, some studies primarily conducted in non-U.S. nations and where English is not the native language, suggest changes in the original factor structure of the CTQ. For example, studies conducted by different research groups in South Korea (Kim, Park, Yang, \& Oh, 2011), Sweden (Gerdner \& Allgulander, 2009), India (Charak \& Koot, 2014), and Brazil 
(Grassi-Oliveira et al., 2014) found that the reverse scored items of physical neglect did not load on to their specific factor. Another study conducted in the Netherlands found that the item on 'molestation' did not load on the factor of sexual abuse and instead loaded on the factor of physical abuse. This item was dropped from the final model while retaining the five-factor structure of the CTQ (Thombs, Bernstein, Lobbestael, \& Arntz, 2009). This specific item was dropped because the literal translation of the term

\section{'molestation' in Dutch lacked a sexual connotation. Of the five dimensions of}

equivalence to test the transcultural usefulness of instruments (i.e., concept, content, semantic, criterion and technical validity) the literal translation of molestation in Dutch lacked semantic equivalence (Flaherty et al., 1988; de Jong \& van Ommeren, 2002). Another research group from the French-speaking Quebec region in Canada faced a similar issue with the semantic validity of the item on 'molestation' wherein the item loaded on the factor of physical abuse rather than on sexual abuse (Paquette, Laporte, Bigras, \& Zoccolillo, 2004). Cognizant of these discrepancies in the factor structure, the present study aimed to investigate the factor structure of the CTQ in an under studied and non-English speaking sample of Burundian adolescents and youth.

\section{Childhood Abuse and Neglect, and Differences Across Gender}

Prevalence rates of abuse and neglect differ across males and females and studies often indicate physical abuse to be higher in males than in females (e.g., Chen \& Wei, 2011; Thompson, Kingree, \& Desai, 2004), and rates of sexual abuse are reported to be higher in females (Haüser, Schmutzer, Brähler, \& Glaesmer, 2011; Pereda et al., 2009). Conversely, higher levels of physical abuse in females were reported in a nationally representative study from the U.S. (Keyes et al., 2012) and higher levels of sexual abuse 
in males in studies from Malaysia, India, and China (Choo, Dunne, Marret, Fleming, \& Wong, 2011; Charak \& Koot, 2014; Leung, Wong, Chen, \& Tang, 2008). In one study from Egypt, no difference was reported in rates of sexual abuse among boys and girls (Afifi et al., 2003). Notably, the latter are all studies from low-and middle-income nations and the results stand in contrast to findings from high-income countries. Few studies assess gender differences in emotional abuse and neglect, and of those that do, either indicate a preponderance of females over males in reporting emotional abuse (Lee \& Kim, 2011) and neglect (Keyes et al., 2012), or found no gender differences on emotional abuse (Haüser et al., 2011). It is important to note that the instruments and/or surveys used to examine prevalence rates across countries were different across these studies, which can also lead to differences in rates. This is a methodological issue that often crops up in comparative studies in the child maltreatment literature. Nonetheless, owing to the lack of specificity in gender differences across different types of childhood abuse and neglect as found in prior studies, the present study aimed to investigate these differences among Burundian youth.

\section{Cumulative Effect of Multiple Types of Abuse and Neglect on Psychopathology}

Numerous studies suggest that the accumulating exposure to different types of maltreatment lead to a cumulative, additive, and detrimental effect on a victim's wellbeing (Charak, Koot, Dvorak, Elklit, \& Elhai, 2015; Danielson et al., 2009). This is supported by the cumulative risk hypothesis that states that higher the number of risk factors a person is exposed to, higher is the potential for negative outcomes (Appleyard, Egeland, van Dulmen, \& Sroufe, 2005; Arata et al., 2007; Rutter, 1979). For example, in a large sample of adolescents, Arata and colleagues (2007) investigated the different 
combination of maltreatment—sexual abuse, physical abuse, emotional and physical neglect, and physical abuse — and their effects on negative affect and externalizing problems, and found that $13 \%$ of adolescents reported multiple types of maltreatment experiences and were higher on symptoms of depression, suicidality, and hopelessness, and were more hostile and displayed more delinquent behavior, in contrast to those with no maltreatment or single type of maltreatment. To date only one study has investigated the cumulative effect of childhood victimization experiences in a sample of children from Africa (Egypt, cf. Afifi, El-Lawindi, Ahmed, \& Basily, 2003). This study assessed three types of abuse, namely, emotional, physical and sexual abuse and found that those adolescents with experiences of 2 or more types of abuse were at a higher risk of hyperactivity, learning disability, and further victimization within and outside the family environment. However, the study by Afifi et al. (2003) did not use a standardized questionnaire to gauge types of maltreatment and did not assess neglect types. In the present study we investigate the additive effect of experiencing multiple types of maltreatment on depression and PTSD symptoms among Burundian youth using standardized questionnaires.

\section{The Current Study}

The present study had the following aims and hypotheses. The first aim was to assess the factor structure of a standardized and popular measure of childhood maltreatment, namely, the Childhood Trauma Questionnaire (CTQ; Bernstein \& Fink, 1998) in a sample of adolescents and youth from the conflict-affected Burundi. To date no study has employed a standardized questionnaire to examine childhood maltreatment in Burundi. With this in mind, we explored the factor structure of the CTQ based on the 
original five-factor intercorrelated model of childhood abuse and neglect, and hypothesized that the five-factor structure of CTQ will be replicated in the current sample (Hypothesis 1). Our second aim was to assess the association between gender of the child and factors of abuse and neglect as obtained via structural equation modeling. We hypothesized that sexual abuse would be higher in girls than in boys, and physical abuse would be higher in boys than in girls, and did not expect to find any gender differences across emotional abuse, emotional and physical neglect (Hypothesis 2). Third, the present study examined the rates of childhood abuse and neglect using the CTQ and compared these rates with prior studies based on the CTQ from developed nations. Based on prior studies suggesting that the level of trauma experienced by children in conflict-affected regions increases, we expected that the rates of childhood abuse and neglect would be significantly higher in the present sample when compared with samples from the highincome nations using the CTQ (Hypothesis 3). Fourth, we aimed to assess the cumulative effect of experiencing multiple types of abuse and neglect on psychopathology, namely, symptoms of depression and PTSD. Based on the cumulative risk hypothesis (Appleyard et al., 2005; Rutter, 1979), we hypothesized that as the number of maltreatment types increase there would be a corresponding increase in depression and PTSD scores (Hypothesis 4).

\section{Methods}

\section{Participants \& Procedure}

The present study is based on a sub-sample of a large study, which had 359 parent-child dyads that were a part of a nationwide study investigating parental caregiving practices in Burundi. Participants were drawn from five provinces (out of the 17), 
namely, Muyinga (northern Burundi), Bururi (Southern Burundi), Bubanza, Cibitoke, and Bujumbura Rural (Western Burundi). Notably, all 17 provinces (today there are 18 provinces) of Burundi were severely affected by the civil war and political violence that followed soon after the civil war. Households were selected based on information shared by a research team who randomly selected 2,050 households (1,350 original and 700split-off households, cf. Jeusette \& Verwimp, 2017) from the Multiple Indicator Cluster Survey (MICS-3) implemented in 2005 by the Burundi National Institute of Statistics and Economics (ISTEEBU). For the present study, the selection criteria for these 2,050 households were (i) those living in the five provinces of Muyinga, Bururi, Bubanza, Cibitoke, and Bujumbura Rural, (ii) with at least one child in the age range of 8-21years, and (iii) an adult parent (either mother or father). Self-report of childhood maltreatment was collected only from index children who were 12 years or older, a requirement of the CTQ: the self-report measure of childhood maltreatment used in the present study.

A final sample of 231 adolescents and youth ( $87 \%$ under the age of 18 years) in the age range of $12-21$ years $(M=14.9, S D=1.99 ; 58.4 \%$ female $)$ were administered the measures used in the present study. On comparing participants in the present study (age range $12-21 ; N=231$ ) with participants who were not administered the CTQ (age range 8-11 years, $N=128$ ), it was found that the older participants were significantly higher on $\operatorname{PTSD}\left(F[1,357]=31.88, p<.001 ; M_{1}=8.78\right.$ vs. $\left.M_{2}=4.84\right)$ and depression scores $(F$ $[1,357]=5.84, p<.05 ; M_{1}=7.97$ vs. $\left.M_{2}=6.58\right)$. Notably, PTSD and depression have

\section{also been found to be higher among older adolescents than younger ones as found in a}

national survey on adolescents from the United States (Merikangas et al., 2010). No 
gender difference was found between the present sample that was older in age, and younger children who were not administered the CTQ $\left(X^{2}[1]=0.37, p=0.31\right)$

Data collection was carried out by 8 male and 8 female interviewers bilingual in French and Kirundi with a University degree and prior experience with survey methods in Burundi. Care was taken to have equal number of interviewers whose ethnic background was Tutsi or Hutu (the two major ethnic groups in Burundi). They received a half-day of additional training on the methodology and measures used in the present study. The training and the interviews took place in March and April 2015, just before the political turmoil related to elections in Burundi commenced. Owing to the long-standing ethnic divisions and violence between the Hutu and the Tutsi groups in Burundi, gathering information on ethnic background could cause a feeling of vulnerability among participants. Hence, in the present study no information of the ethnic background of the participants was collected and no attempt was made to match the ethnic background of interviewers and interviewees. The interviewers took verbal informed consent from all adult participants and verbal assent from adolescents. Written consent was not collected as studies suggest that in cross-cultural research especially among vulnerable populations, such as ethnic minorities, and refugees, written signed consent can be intimidating as it is the only documentation that can reveal one's identity and potentially breach confidentiality (Liamputtong, 2008). The study protocol was in line with the ethical guidelines provided by UNICEF and the University of Amsterdam. Approval was also provided by the Ministry of Community Development in Burundi.

Over a period of two days, the CTQ (see section on measures) was translated from French to Kirundi language by the interviewers who were bilingual in both the 
languages. Two Psychologists who moderated the group were bilingual in French and

Kirundi language, and translated and back translated the CTQ. Each item in Kirundi was followed by extensive discussions in the group until all members reached an agreement that the items would have semantic, conceptual and content equivalence across different socio-economic strata of the society. Notably, French and Kirundi are the two most widely spoken official languages in Burundi. English as a third official language was only recently introduced in 2014, and has little active presence in Burundi (IWACU English News, 2014). For depression we used the Depression Self-Rating Scale (DSRS), and for PTSD the Child PTSD Symptom Scale (CPSS). Both instruments were previously translated, back translated, piloted and validated in Kirundi (Ventevogel, Komproe, Jordans, Feo, \& de Jong, 2014). Like the CTQ, all the depression and PTSD items were discussed by the group of bilingual professionals, and slightly adapted when the group thought it to be necessary. We chose this procedure because psychological jargon is a relatively recent phenomenon in Kirundi and therefore prone to slight modifications over time.

\section{Measures}

Brief demographic details. A sheet inquiring about the participant's age, gender, and province of residence was administered. No other demographic details were available.

Childhood maltreatment. The Childhood Trauma Questionnaire-short form (CTQ; Bernstein \& Fink, 1998; Bernstein et al., 2003) has 25 self-report items assessing childhood abuse and neglect and can be administered to anyone 12 years or older. The present study used the French adaptation of the CTQ (Paquette, Laporte, Bigras, \& 
Zoccolillo, 2004) since French is the most widely spoken foreign language in Burundi, and translation to Kirundi, the native language of Burundi, was possible due to the availability of trained psychologists fluent in French and Kirundi. There are five subscales in the CTQ, namely, emotional abuse, physical abuse, sexual abuse, emotional neglect, and physical neglect, and each subscale comprises of 5 items with a response option of a 5-point Likert scale from 'Never true' to 'Very often true' (1-5) with the precursor statement being 'When I was growing up.' The CTQ demonstrates good reliability, with an internal consistency reliability coefficient ranging from a median 0.66 to 0.92 across a range of seven different samples, and a test-retest reliability coefficient ranging from 0.79 to 0.86 over an average period of 3.6 months (Bernstein et al., 2003). In a French-speaking sample from Montreal in Canada, the Cronbach's alpha ranged from 0.68 to 0.91 , and test-retest reliability was excellent, ranging between $0.73-0.94$ for the five subscales of the CTQ (Paquette et al., 2004). In addition, the convergent validity is indicated by significant correlations of the CTQ scores with other trauma measures such as the clinician-rated interviews and therapist ratings of abuse and neglect (Bernstein \& Fink, 1998; Bernstein et al., 2003). Cronbach's alpha of the different subtypes of abuse and neglect for the present sample were moderate and are reported in Table 1.

During adaptation of the CTQ in Kirundi language, the team after extensive deliberation added the word 'kenshi' (referring to 'often' in English) to item 24 comprising the subscale of sexual abuse (see Table 1). According to the population norm, a single event of sexual abuse was perceived as so common by the interviewers that they thought that participants might not consider it worth reporting. They therefore added the 
word 'kenshi' that means often, and the item literally translated to 'I was often sexually abused.' Notably, this item differed from item 27 assessing perception of sexual abuse, which literally translated to 'I believe I was sexually abused.'

Dichotomous measures of 'no EA/PA/SA/EN/PN' coded as '0' and the 'presence of EA/PA/SA/EN/PN' coded as ' 1 ' for all five types of abuse and neglect were created using the classification specified by the authors of the scale (cf. Bernstein \& Fink, 1998) for assessing prevalence rates and number of maltreatment types experienced.

Depressive symptoms. The Depression Self-Rating Scale (DSRS) is an 18-item self-report measure to assess depressive symptoms among children and adolescents (Birleson, 1981). Participants are asked to best describe their feelings in the past two weeks on a scale ranging from 0 (never) to 2 (mostly). The score obtained across the 18items are summed to get a total score. The test-retest reliability of the scale has been found to be 0.80 , the split-half reliability was 0.86 , and it had a sensitivity of $66.7 \%$ and specificity of $76.7 \%$ (Birleson, 1981). A cut-off score of 19 and above is likely to lead to a diagnosis of major depressive disorder or Dysthymia in children and adolescents from Burundi (Ventevogel et al., 2014). Cronbach's alpha in the present study was 0.84 .

Posttraumatic stress symptoms. The Child PTSD Symptom Scale-Part-I (CPSS; Foa, Johnson, Feeny, \& Treadwell, 2001) assesses symptoms of DSM IV Posttraumatic stress disorder (American Psychiatric Association [APA], 1994) with 17 items. Participants are instructed to rate the symptoms for the past two weeks from 0 (Not at all or only at one time) to 3 (5 or more times a week/almost always) in the context of an upsetting event. The Cronbach's alpha was 0.89 for the total score, 0.80 for reexperiencing, 0.73 for avoidance, and 0.70 for arousal. The test-retest reliability for the 
PTSD was moderate, with a kappa of 0.55 (Foa et al., 2001). Previously in a sample of school-going children from Burundi the cut-off score of 26 demonstrated good sensitivity and specificity (Ventevogel et al., 2014). In the present study, Cronbach's alpha for the total score was 0.80 , for re-experiencing 0.82 , avoidance 0.72 , and hyperarousal 0.71 .

\section{Analytic Plan}

Descriptive statistics were conducted in IBM SPSS version 20.0. Mplus 7.2 software (Muthén \& Muthén, 2016) was used to conduct the confirmatory factor analysis (CFA) and the multiple indicators multiple causes (MIMIC), an application of structural equation modeling (Muthén, 1989). The MIMIC model assessed the effect of gender on the latent factor of the CTQ. This model was carried out in two steps. First, an assessment of the factor structure of the CTQ based on the existing five-factor intercorrelated model (Bernstein \& Fink, 1998) was carried out via CFA. A weighted least square approach with the estimator as the weighted least square with mean and variance adjusted (WLSMV) was used as the items were ordinal Likert scale. For this CFA model estimation, factor loadings were freely estimated, factor variances were fixed to one, error covariances were fixed to zero and all factors were intercorrelated. Robust versions of goodness-of-fit indices including the comparative fit index (CFI), Tucker-Lewis index (TLI), and the root mean square error of approximation (RMSEA) were applied to determine the best fitting model. As recommended by Hu and Bentler (1999) excellent (or adequate) fit of the model is obtained when CFI and TLI $\leq 0.95(0.90-0.94)$, and RMSEA $<0.06$ (0.07-0.08). Second, after obtaining the best fitting model, gender was added as a covariate to the CFA model of the CTQ (i.e., MIMIC model) and simultaneous tests of the relation between gender and the latent factors of the CTQ was 
carried out. Third, based on z-tests for proportions comparison of rates of childhood abuse and neglect (based on the CTQ) found in the present study, comparative analyses with data from existing studies from high-income nations, namely Germany (Häuser et al., 2011), Canada (Paivio \& Cramer, 2004), and Korea (Kim et al., 2011) were conducted. Fourth, to assess the cumulative effect of different types of maltreatment on depression and PTSD symptoms, one-way analysis of variance (ANOVA) was carried out with a post-hoc analysis.

\section{Results}

There was only one missing value on the CTQ.

\section{Factor structure of the CTQ and the MIMIC model}

The original five-factor intercorrelated model of the CTQ (Bernstein \& Fink, 1998; Bernstein et al., 2003) was tested using CFA. The model did not converge and item 24 (Someone molested me), part of the original sexual abuse factor was found to be problematic with a negative residual variance. The factor loading of item 24 was greater than 1 , and indicated a linear dependency with this item and the latent factor of sexual abuse. Next we tested a CFA model of the five-factor model of the CTQ after dropping an item from the sexual abuse factor (i.e., item 24: 'someone molested me'). This lead to a model with adequate fit, $X^{2}(242,231)=451.90, \mathrm{CFI} / \mathrm{TLI}=0.94 / 0.93, \mathrm{RMSEA}=0.06$ $[90 \% \mathrm{CI}=0.05-0.07]$. The standardized factor loadings and factor intercorrelations are presented in Tables 1 and 2, respectively.

For the MIMIC model, we tested the effect of gender on factors of emotional, physical, and sexual abuse and emotional and physical neglect. Addition of gender as a covariate to the CFA model lead to a model with adequate fit without alterations with the 
factor structure of CTQ, $X^{2}(261,231)=488.62, \mathrm{CFI} / \mathrm{TLI}=0.94 / 0.93, \mathrm{RMSEA}=0.06$ $[90 \% \mathrm{CI}=0.05-0.07]$

\section{Rates of Maltreatment Types and Comparison with Other High-income Nations}

All participants reported experiencing at least one type of abuse and/or neglect. Nearly $14 \%$ reported having experienced two types of abuse or neglect, another $47.6 \%$ had faced three types of abuse/neglect, and additional $22.1 \%$ and $15.2 \%$ had experienced four and five types of abuse and neglect, respectively. Specifically, nearly $32 \%$ of the youth (11.3\% male vs. $20.8 \%$ female) reported experiencing emotional abuse, $20.8 \%$ (11.3\% male vs. $9.5 \%$ female) reported physical abuse, $14.7 \%$ reported sexual abuse (32.4\% male and $67.6 \%$ female), $93.5 \%$ had faced emotional neglect (39\% male vs. $54.5 \%$ female), and $89.2 \%$ reported physical neglect ( $37.7 \%$ male vs. $51.5 \%$ female).

Based on $z$-tests for proportions when comparing rates of childhood abuse and neglect found in the present study with data from existing studies from high-income nations we found the following results. In contrast to the CTQ data from a representative sample from Germany (cf. Häuser et al., 2011, Table 2), the present sample of adolescents and youth were significantly higher on emotional abuse $(z=6.72, p<0.001)$, physical abuse $(z=3.26, p<0.001)$, emotional neglect $(z=12.87, p<0.001)$, and physical neglect $(z=11.89, p<0.001)$. Compared with prevalence rates of childhood abuse and neglect in an undergraduate student sample from Canada (cf. Paivio \& Cramer, 2004), it was found that the Burundian adolescents in the present study were higher on emotional neglect $(z=13.29, p<0.001)$ and physical neglect $(z=18.52, p<0.001)$. No difference was found across emotional, physical and sexual abuse. Similarly, compared to a psychiatric outpatient adult sample from South Korea (cf. Kim et al., 2011, p.307), the 
present sample had significantly higher rates of emotional abuse $(z=3.42, p<0.001)$, sexual abuse $(z=2.03, p<0.05)$, emotional neglect $(z=10.05, p<0.001)$, and physical $\operatorname{neglect}(z=6.65, p<0.001)$.

\section{Cumulative Effect of Multiple Types of Maltreatment on Depression, and PTSD Symptoms}

As per the cut-off scores, $5.2 \%$ of the adolescents had diagnosable depression and 2.2\% had PTSD. Table 4 shows the mean and standard deviation scores across those with $1,2,3,4$ and 5 types of maltreatment experiences on depression $(F[4,226]=29.09, p<$ 0.001), and PTSD symptoms $(F[4,226]=23.63, p<0.001)$. Post-hoc analyses (with Bonferroni's correction term) indicated that there was no significant linear increase in scores on psychopathology as the number of maltreatment types increased. However, it is noteworthy that those adolescents who endorsed 4 and 5 types of maltreatment (or polyvictimization; Finkelhor, Ormrod, \& Turner, 2007, 2009) were higher on depression, and PTSD symptoms compared to those who endorsed experiencing three or lesser number of types of maltreatment.

\section{Discussion}

The present study examined the factor structure of a standardized questionnaire, the CTQ, for assessing childhood abuse and neglect, and its association with gender in an understudied sample of adolescents and youth from five provinces of Burundi in the great lake region of Africa. In addition, rates of five different types of maltreatment, including emotional, physical, and sexual abuse, and emotional and physical neglect were assessed and compared with studies from developed nations using the same standardized measure as in the present study, namely, the CTQ. Findings supported a five-factor intercorrelated 
model of the CTQ after dropping one item related to 'molestation'. The only difference across gender was found on physical abuse with boys scoring higher than girls. Compared to rates of childhood maltreatment from high-income nations, such as Germany, Canada, and South Korea the rates of all types of neglect were higher in the current sample of adolescents and youth from Burundi. The current findings also support the cumulative effect of experiencing four or more types of childhood abuse and neglect on depression, and PTSD symptoms.

The first hypothesis that the original factor structure of the CTQ would be replicated in the Burundian sample was partially supported. After dropping an item related to sexual molestation, the five-factor intercorrelated model of the CTQ was the best solution for the present sample. Two prior studies one based on an adult clinical sample from the Netherlands and another in a French-speaking Canadian sample, found the item on molestation (comprising the factor of sexual abuse) to be problematic and this was attributed to translation of the word 'molestation' in the Dutch and French language, which lacked sexual connotations meant to be associated with the term (Paquette et al., 2004; Thombs et al., 2009). In the present study we did take care and specify the sexual connotation associated with this item when translating it into the Kirundi language, yet the item had negative residual variance and a factor loading greater than 1 suggestive of model misspecification due to linear dependency between the item and the latent construct of sexual abuse. Perhaps, due to the broad meaning of sexual molestation and it comprising many aspects of sexual abuse (e.g., unwanted fondling, touching, coerced sexual activity, made to do or watch sexually activities or pictures), it displayed linear dependency with the latent factor of sexual abuse. Hence, the item on molestation was 
dropped from the model in the present study, and the remaining items loaded well on to their respective factors. We posit that the problem may not be the semantic validity of the item (i.e., the meaning of the term molestation being different in Burundi as compared to the cultures where the scale was developed, Kohrt et al., 2011), and the original item in English would benefit from rewording representative of specific behaviors related to sexual molestation. By providing behaviorally specific words and examples on the original scale-item, future translations into different languages would be better equipped to maintain sematic equivalence by using relevant examples or culturally appropriate idioms. In all, after dropping the one item, the CTQ model found in the present study had close semblance to the original factor structure of the CTQ.

Our second hypothesis examining gender differences in physical and sexual abuse was partially supported, such that, in comparison to girls, boys were higher on physical abuse. This is in line with a number of prior research studies from across the world (Chen \& Wei, 2011; Lee \& Kim, 2011). The absence of any significant difference in sexual abuse among boys and girls in the present study, although in contrast to our hypothesis and the extant literature from the West (e.g., Haüser et al., 2011; Pereda et al., 2009), is supported by findings from school-going students from Zimbabwe (Gwirayi, 2013). More recently studies have started to highlight the high prevalence of sexual abuse among males from Malaysia, India, and China (Charak \& Koot, 2014; Choo et al., 2011; Leung et al., 2008). Future studies should focus on examining prevalence rates and cultural understanding of sexual abuse among boys and girls. With regard to emotional abuse and neglect, no difference was found across Burundian boys and girls. These findings add to the handful of studies that suggest no differences between boys and girls on emotional 
abuse (Haüser et al., 2011) and neglect (Charak \& Koot, 2014). Future studies should continue to examine prevalence rates and gender differences (if any) in these understudied maltreatment types, namely, neglect and emotional abuse.

The Burundian adolescents reported higher abuse and neglect experiences compared to reports from high-income countries thus supporting hypothesis 3 . The present findings indicated that the rates of maltreatment, especially emotional maltreatment and physical neglect, was three to four times higher than those found in high-income nations based on the CTQ. In comparison to samples from Germany and South Korea, the present sample of Burundian adolescents reported higher rates of emotional and sexual abuse, emotional and physical neglect. Higher rates of physical and emotional abuse may be attributable to societal sanctioning of corporal punishment and verbal assault (Song, Tol, \& de Jong, 2014), which may be culturally acceptable, nonetheless negatively affects the wellbeing of children (Hecker, Radtke, Hermenau, Papassotiropoulos, \& Elbert, 2016). Additionally, the prevailing political instability, violence, and lack of resources in the country maybe a reason for higher reports of emotional and physical neglect (Crombach, Bambonye, \& Elbert, 2014). Notably, the present sample of adolescents reported rates of physical (20.8\%) and sexual abuse $(14.7 \%)$ in the range reported by a recent systematic review on physical and sexual abuse among children in Africa (7.6-45\% of physical abuse and 1.6-77.7\% sexual abuse, see Meinck et al 2015). It may also be the case that in the present study with the use of word 'kenshi' (referring to 'often') for assessing sexual abuse, the rates of sexual abuse dropped and the actual rates maybe higher. In the absence of any large-scale study assessing child abuse and neglect among youth from Burundi (nor neighboring countries, 
such as Rwanda, culturally and linguistically similar to Burundi), no direct comparison with other national surveys could be carried out. Future studies should focus on assessing rates and norm scores of different types of abuse and neglect among adolescents and youth using standardized, validated, and culturally sensitive questionnaires for comparison studies and for preventative interventions to be formulated.

In support of the cumulative risk hypothesis, the present findings suggested that those with multiple types of abuse and neglect experiences score higher on depression and PTSD symptoms (hypothesis 4 partially supported). To the best of our knowledge, only one study from Africa (i.e., Egypt) to date has investigated the effect of multiple types of abuse, namely, physical, sexual and emotional abuse, among adolescents and supported the cumulative effect of multiple types of maltreatment on a child's wellbeing (e.g., Afifi et al., 2003). Our findings corroborate and add to the literature focusing on the cumulative effect of different types of childhood abuse and neglect. Notably, there was no linear increase in risk of psychological problems as the number of types of maltreatment experiences increased. Hence, hypothesis 4 was partially supported, in that when a participant had experienced 4 or more types of abuse or neglect or polyvictimization (Finkelhor et al., 2007, 2009) the cumulative effect of maltreatment experiences on psychopathology emerged.

The present findings should be considered in light of the following limitations. First, the households in the present study were from five out of the then 17 provinces of Burundi. Although all provinces in Burundi have been affected by the civil war and the political violence that followed, current study findings may not be generalizable to the whole population of Burundi. Second, the study design initially was a longitudinal 
design; however, data collection was interrupted due to eruption of political violence leading to the present study being cross-sectional in nature from time-point 1 . Hence, causality of maltreatment types leading to depression, and PTSD is an assumption based on the cumulative risk theory (Higgins \& McCabe, 2001). Additionally, the present study is limited in information on demographic details of participants, such as, parental education, socio-economic status, family structure and density of household, variables that are identified risk factors for childhood abuse and neglect (Alink et al., 2013; Charak \& Koot, 2014). Third, childhood maltreatment was explored through a self-report questionnaire that may introduce the possibility of response bias resulting from the inability of an individual to recall victimization (Widom \& Morris, 1997). Notably, the maltreatment self-report questionnaire used in the present study, namely the CTQ, has most items that ask behavior specific questions, which tend to reduce response bias.

The present study has important implications at a theoretical, clinical, and policylevel. First, the present study answers the call for more empirical based evidence from low-and middle-income nations (Zolotor et al., 2009) by examining the factor structure of a standardized questionnaire measuring childhood abuse and neglect, and related gender differences. The present findings call for more culturally sensitive questionnaires measuring childhood abuse and neglect especially when assessing sexual abuse, as the likelihood of reporting any incident may be colored by the perception of stigma and reporting a single incident of sexual abuse maybe considered as a concept that is foreign. This can prove problematic as it can lead to further (re)victimization of the child. By using a standardized questionnaire, such as the CTQ, comparison of maltreatment rates with other studies based on the same tool was possible in the present study. Related 
findings indicated that the Burundian adolescents were higher on emotional maltreatment, physical abuse and neglect when compared with studies from high-income nations. Findings highlight the need for preventative strategies (e.g., awareness programs through community engagement) in Burundi. Second, focus should also be on imparting parenting skills to develop alternate ways of discipline rather than the use of harsh punishment or verbal abuse. Clinical interventions should be provided to at-risk adolescents and youth, that is, those with poly-victimization experiences and scoring higher on psychological problems. Training of professional, paraprofessionals, and people from communities to identify at-risk children and situations, provision of traumainformed care to parents and children should be carried out. For example, a recent study found support for brief interventions comprising psycho education of parents in preventing child maltreatment and reducing behavioral problems in children (Jordans, Tol, Ndayisaba, \& Komproe, 2013). Third, at a policy-level, international organizations and local governments need to continue their efforts to make the region a less volatile environment and resources need to be directed towards making health care services accessible to survivors of child maltreatment, while simultaneously developing child maltreatment preventative strategies. 


\section{References}

Affifi, Z., El-Lawindi, M., Ahmed, S., \& Basily, W. (2003). Adolescent abuse in a community sample in Beni Suef, Egypt. Prevalence and risk factors. Eastern Mediterranean Health Journal, 9, 1003-1017.

Alink, L. R. A., Euser, S., van IJzendoorn, M. H., Bakermans-Kranenburg, M. J. (2013). Is elevated risk of child maltreatment in immigrant families associated with socioeconomic status? Evidence from three sources. International Journal of Psychology, 48, 117-127.

Appleyard, K., Egeland, B., van Dulmen, M., \& Sroufe, A. (2005). When more is not better: the role of cumulative risk in child behavior outcomes. Journal of Child Psychology and Psychiatry, 46, 235-245.

Berckmoes, L. H. (2014). Elusive tactics: Urban youth navigating the aftermath of war in Burundi. Unpublished Ph.D. dissertation. Amsterdam: VU University.

Berckmoes, L. H. (2015). Youth, politics and violence in Burundi: Gullible followers or tactics actors? In: L'Afrique des Grands Lacs: Annuaire 2014-2015, 21-38. Antwerp: University of Antwerp Press.

Bernstein, D. P., \& Fink, L. (1998). Childhood trauma questionnaire: A retrospective self-report manual. San Antonio, TX: The Psychological Corporation.

Bernstein, D. P., Stein, J. A., Newcomb, M. D., Walker, E., Pogge, D., Ahluvalia, T...Zule, W. (2003). Development and validation of a brief screening version of the Childhood Trauma Questionnaire. Child Abuse and Neglect, 27, 169-190.

Birleson, P. (1981). The validity of depressive disorder in childhood and the development of a self-rating scale: a research report. Journal of Child Psychology and Psychiatry, 22, 73-88. 
Bogaerts, S., Daalder, A. L., Spreen, M., van der Knapp, L. M., \& Henrichs, J. (2011). Factor structure of the Dutch version of the childhood trauma questionnaire-SF among female sex workers in the Netherlands. Journal of Forensic Psychology Practice, 11, 432-442.

Catani, C., Jacob, N., Schauer, E., Kohila, M., \& Neuner, F. (2008). Family violence, war, and natural disasters: A study of the effect of extreme stress on children's mental health in Sri Lanka. BMC Psychiatry, 8, 33-43.

Charak, R., \& Koot, H. M. (2014). Abuse and neglect in adolescents of Jammu, India: The role of gender, family structure, and parental education. Journal of Anxiety Disorders, 28, 590-598.

Charak, R., \& Koot, H. M. (2015). Severity of maltreatment and personality pathology in adolescents of Jammu, India: A latent class approach. Child Abuse and Neglect, 50, 56-66.

Charak, R., Koot, H. M., Dvorak, R. D., Elklit, A., \& Elhai, J. D. (2015). Unique versus cumulative effects of physical and sexual assault on patterns of adolescent substance use. Psychiatry Research, 230, 763-769.

Chen, J. K., \& Wei, H. S. (2011). Student victimization by teachers in Taiwan: prevalence and associations. Child Abuse and Neglect, 35, 382-390.

Choo, W. Y., Dunne, M. P., Marret, M. J., Fleming, M., \& Wong, Y. L. (2011). Victimization experiences of adolescents in Malaysia. Journal of Adolescent Health, 49, 627-634.

Crombach, A., Bambonye, M., \& Elbert, T. (2014). A study on reintegration of street children in Burundi: experienced violence and maltreatment are associated with 
mental health impairments and impeded educational progress. Frontiers in Psychology, 5, 1441. doi:10.3389/fpsyg.2014.01441

Crombach, A. \& Bambonyé, M. (2015) Intergenerational violence in Burundi: Experienced childhood maltreatment increases the risk of abusive child rearing and intimate partner violence. European Journal of Psychotraumatology, 6. doi:10.3402/ejpt.v6.26995

de Jong, J. T. V. M., \& van Ommeren, M. (2002). Toward a culture-informed epidemiology: combining qualitative and quantitative research in transcultural contexts. Transcultural Psychiatry, 39, 422-433.

Finkelhor, D., Ormrod, R. K., \& Turner, H. A. (2009). Lifetime assessment of polyvictimization in a national sample of children and youth. Child Abuse and Neglect, $33,403-411$.

Finkelhor, D., Ormrod, R. K., \& Turner, H. A. (2007). Poly-victimization: A neglected component in child victimization. Child Abuse and Neglect, 31, 7-26.

Flaherty, J. A., Gavira, F. M., Pathak, D., Mitchell, T.,Wintrob, R., Richman, J. A., \& Birz, S. (1988). Developing instruments for cross-cultural psychiatric research. Journal of Nervous and Mental Disease, 176, 257-263.

Foa, E. B., Johnson, K. M., Feeny, N. C., \& Treadwell, K. R. H. (2001). The Child PTSD symptoms scale: a preliminary examination of its psychometric properties. Journal of Clinical Child Psychology, 30, 376-384.

Forde, D. R., Baron, S. W., Scher, C. D., \& Stein, M. B. (2012). Factor structure and reliability of the childhood trauma questionnaire and prevalence estimates of 
trauma for male and female street youth. Journal of Interpersonal Violence, 27, 364-379.

Fraser, G. \& P.L. Kilbride (1980) Child abuse and neglect rare, but perhaps increasing, phenomena among the Samia of Kenya, Child Abuse and Neglect, 4, 227-232.

Gerdner, A., \& Allgulander, C. (2009). Psychometric properties of the Swedish version of the childhood trauma questionnaire-short form (CTQ-SF). Nordic Journal of Psychiatry, 63, 160-170.

Grassi-Oliveira, R., Cogo-Moreira, H., Salum, G. A., Brietzke, E., Viola, T. W., Manfro, G. G.,...Arteche, A. X. (2014). Childhood trauma questionnaire (CTQ) in Brazilian samples of different age groups: Findings from confirmatory factor analysis. PLOS One, 9, e87118, doi:10.1371/journal.pone.0087118

Gwirayi, P. (2013). The prevalence of child sexual abuse among secondary school pupils in Gweru, Zimbabwe. Journal of Sexual Aggression, 19, 253-263.

Häuser, W., Schmutzer, G., Brähler, E., \& Glaesmer, H. (2011). Maltreatment in childhood and adolescence: result from a survey of representative sample of the German population. Deutsches Arzteblatt International, 108, 287-294.

Hecker, T., Radtke, K. M., Hermenau, K., Papassotiropoulos, A., \& Elbert, T. (2016). Associations among child abuse, mental health, and epigenetic modifications in the proopiomelanocortin gene (POMC): A study with children in Tanzania. Development and Psychopathology. doi. 10.1017/S0954579415001248

Hermenau, K., Eggert, I., Landolt, M. A., \& Hecker, T. (2015). Neglect and perceived stigmatization impact psychological distress of orphans in Tanzania. European Journal of Psychotraumatology, 6. 
Hu, L., \& Bentler, P. M. (1999). Cutoff criteria versus new alternatives. Structural Equation Modeling, 6, 1-55.

Human Rights Watch (2010) Closing Doors? The Narrowing of Democratic Space in Burundi, 23 November. New York: HRW.

IBM Corp. (2011). IBM SPSS statistics for windows, version 20.0. Armonk, New York: IBM Corp.

Jeusette, L., \& Verwimp, P. (2017). Childhood aspirations, occupational outcomes and exposure to violence: evidence from Burundi. Retrieved from www.hicn.org/wordpress/?page_id=28

Jordans, M. J. D., Tol, W. A., Ndayisaba, A., \& Komproe, I. H. (2013). A controlled evaluation of a brief parenting psychoeducation intervention in Burundi. Social Psychiatry and Psychiatric Epidemiology, 48, 1851-1859.

Keyes, K. M., Eaton, N. R., Krueger, R. F., Mc Laughlin, K. A., Wall, M. M., Grant, B. F., \& Hasin, D. S. (2012). Childhood maltreatment and the structure of common psychiatric disorders. The British Journal of Psychiatry, 200, 107-115.

Kim, D., Park, S., Yang, H., \& Oh, D. H. (2011). Reliability and validity of the Korean version of the childhood trauma questionnaire-short form for psychiatric outpatients. Psychiatry Investigation, 8, 305-311.

Kohrt, B. A., Jordans, M. J. D., Tol, W. A., Luitel, N. P., Maharjan, S. M., \& Upadhaya, N. (2011). Validation of cross-cultural child mental health and psychosocial research instruments: Adapting the Depression Self-Rating Scale and Child PTSD Symptom Scale in Nepal. BMC Psychiatry, 11, 127. doi: 10.1186/1471-244X-11127. 
Laird, S. E. (2016). Protecting children from nutritional and medical neglect in subSaharan Africa: A five-country study. International Journal of Social Welfare, 25, $47-57$.

Lee, Y., \& Kim, S. (2011). Childhood maltreatment in South Korea: retrospective study. Child Abuse and Neglect, 35, 1037-1044.

Leung, P. W. S., Wong, W. C. W., Cohen, W. Q., \& Tang, C. S. K. (2008). Prevalence and determinants of child maltreatment among high school students in Southern China: a large scale school based survey. Child and Adolescent Psychiatry and Mental Health. doi.org/10.1186/1753-2000-2-27.

Liamputtong, P. (2008). Doing research in a cross-cultural context: Methodological and ethical challenges. In P. Liamputtong (Eds.), Doing cross-cultural research (p. 320). Dordrecht, The Netherlands: Springer.

Meinck, F., Cluver, L. D., Boyes, M. E., \& Mhlongo, E. L. (2015). Risk and protective factors for physical and sexual abuse of children and adolescents in Africa: a review and implications for practice. Trauma, Violence, and Abuse, 16, 81-107.

Merikangas, K. R., He, J., Burstein, M., Swanson, S. A., Avenevoli, S., Cui, L., \& ... Swendsen, J. (2010). Lifetime prevalence of mental disorders in U.S. adolescents: Results from the National Comorbidity Survey Replication-Adolescent Supplement (NCS-A). Journal of the American Academy of Child and Adolescent Psychiatry, 49, 980-989.

Muthén, B. O. (1989). Latent variable modeling in heterogeneous populations. Psychometrika, 54, 557-585.

Muthén, B. O., \& Muthén, L. K. (2016). Mplus version 7.2. Los Angeles, CA: Author. 
Nichols, J., Embleton, L., Mwangi, A., Morantz, G., Vreeman, R., Ayaya, S.,...Braitse Ayuku, D., et al. (2014). Physical and sexual abuse in orphaned compared to nonorphaned children in sub-Saharan Africa: A systematic review and meta-analysis. Child Abuse and Neglect, 38, 304-316.

Oxford Poverty and Human Development Initiative (2016). Burundi Country Briefing: multidimensional poverty index data bank. University of Oxford: Author. Retrieved from http://www.dataforall.org/dashboard/ophi/index.php/mpi/country briefings , accessed 9 October 2016.

Paivio, S. C., \& Cramer, K. M. (2004). Factor structure and reliability of the childhood trauma questionnaire in a Canadian undergraduate student sample. Child Abuse and Neglect, 28, 889-904.

Paquette, D., Laporte, L., Bigras, M., \& Zoccolillo, M. (2004). Validation de la version française du CTQ et prévalence de l'histoire de maltraitance. Santé Mentale au Québec, 29, 201-220.

Pereda, N., Guilera, G., Forns, M., \& Gomez-Benito, J. (2009). The international epidemiology of child sexual abuse: a continuation of Finkelhor (1994). Child Abuse and Neglect, 33, 331-342.

Petrenko, C. L. M., Friend, A., Garrido, E. F., Taussig, H. N., \& Culhane, S. E. (2012). Does subtype matter? Assessing the effects of maltreatment on functioning in preadolescent youth in out-of-home care. Child Abuse and Neglect, 36, 633-644.

Rutter, M. (1979). Protective factors in children's responses to stress and disadvantage. In Kent, M. W., Rolf, J. E., (Eds.), Primary prevention of psychopathology. Vol. 3: 
Social competence in children (pp. 49-74). New Hampshire: University of New England Press Hover.

Saile, R., Ertl, V., Neuner, F., \& Catani, C. (2014). Does war contribute to family violence against children? Findings from a two-generational multi-informant study in Northern Uganda. Child Abuse and Neglect, 38, 135-146.

Song, S. J., Tol, W., \& De Jong, J. T. V. M. (2014). Indero: Intergenerational trauma and resilience between Burundian former child soldiers and their children. Family Process, 53, 239-251.

Stoltenborgh, M., Bakermans-Kranenburg, M. J., IJzendoorn, M. H. van, \& Alink, L. R. A. (2013). Cultural-geographical differences in the occurrence of child physical abuse? A meta-analysis of global prevalence. International Journal of Psychology, $48,81-94$.

Thombs, B. D., Bernstein, D. P., Lobbestael, J., \& Arntz, A. (2009). A validation study of the Dutch Childhood trauma questionnaire-short form: Factor structure, reliability, and known-groups validity. Child Abuse and Neglect, 33, 518-523.

Thompson, M. P., Kingree, J. B., \& Desai, S. (2004). Gender differences in long-term health consequences of physical abuse of children: data from a nationally representative survey. American Journal of Public Health, 94, 599-604.

Uwimana, D. (2014, September 17). English is now official language of Burundi. IWACU English News. Retrieved from

http://www.iwacu-burundi.org/englishnews/english-is-now-official-language-of-burundi/ UNHCR (2016, March 4). Number of Burundian refugees tops 250,000 since April. Retrieved from http://www.unhcr.org/news/latest/2016/3/56d97f2d9/numberburundian-refugees-tops-250000-since-april.html. 
UN (2016, April 1). Security Council requests options on deploying UN police in crisistorn Burundi. Retrieved from http://www.un.org/apps/news/story.asp?NewsID=53600\#.V_qYc2V5Bp8.

Ventevogel, P., Komproe, I. H., Jordans, M. J., Feo, P. \& de Jong, J. T. V. M. (2014). Validation of the Kirundi versions of brief self-rating scales for common mental disorders among children in Burundi. BMC Psychiatry, 14, 36. doi: 10.1186/1471244X-14-36.

Verwimp, Ph. \& Burndervoet, T. (2009). Civil War and the Welfare of Extended Households: Evidence from Longitudinal Data from Burundi, Households in Conflict Working Paper 70, University of Sussex, Brighton, United Kingdom.

Widom, C. S., \& Morris, S. (1997). Accuracy of adult recollections of childhood victimization: Part 2. Childhood sexual abuse. Psychological Assessment, 9, 3446.

Worldbank, Data Bank, www.data.worldbank.org, accessed 9 October 2016.

World Health Organization. (2011). Mental health atlas 2011. In WHO (Ed.). Geneva, Switzerland: Author

Youssef, R., Attia, M., \& Kamel, M. (1998). Children experiencing violence I: parental use of corporal punishment. Child Abuse and Neglect, 22, 959-973.

Zolotor, A. J., Runyan, D. K., Dunne, M. P., Jain, D., Peturs, H. R., Ramirez, C...Isaeva, O. (2009). ISPCAN child abuse screening tool children's version (ICAST-C): instrument development and multi-national pilot testing. Child Abuse and Neglect, $33,833-841$. 
Table 1

Mean, SD, Skewness, Kurtosis, and Standardized Factor Loadings for the Five-factor of the CTQ Among Youth from Burundi

\begin{tabular}{llll}
\hline Items of CTQ & Mean/SD & Original five- & Modified five-factor \\
& (skewness/kurtosis) & factor model & model
\end{tabular}

Emotional Abuse $(\mathrm{EA} ; \alpha=0.76)$
3. called names
8. never born
14. hurtful things
18. felt hated
25. emotionally abused
Physical abuse (PA; $\alpha=0.78)$
9. hit
11. bruises
12. hard objects

$7.95 / 3.32(1.25 / 0.84)$

$1.74 / 1.03(1.07 /-.18)$

$0.66 \quad 0.66$

$1.13 / 0.55(4.28 / 17.4) \quad 0.58 \quad 0.58$

$\begin{array}{lll}1.97 / 1.02(1.39 / 0.52) & 0.74 & 0.75\end{array}$

$\begin{array}{lll}1.62 / 1.01(1.39 / 0.52) & 0.84 & 0.84\end{array}$

$\begin{array}{lll}1.49 / 0.94(1.88 / 2.48) & 0.88 & 0.88\end{array}$

$6.75 / 2.75(2.40 / 6.75)$

$\begin{array}{lll}1.22 / 0.67(3.31 / 10.72) & 0.83 & 0.83\end{array}$

$\begin{array}{lll}1.23 / 0.64(2.99 / 9.15) & 0.89 & 0.89\end{array}$

$\begin{array}{lll}1.65 / 0.87(1.08 / 0.01) & 0.49 & 0.49\end{array}$ 


\begin{tabular}{|c|c|c|c|}
\hline 15. physically abused & $1.32 / 0.74(2.31 / 4.43)$ & 0.93 & 0.93 \\
\hline 17. hit badly & $1.32 / 0.81(2.47 / 5.09)$ & 0.79 & 0.79 \\
\hline Sexual abuse ${ }^{\dagger}(\mathrm{SA} ; \alpha=0.80)$ & $4.47 / 1.48$ (3.99/17.33) & & \\
\hline 20. touch sexually & $1.13 / 0.51(4.45 / 21.98)$ & 0.95 & 0.96 \\
\hline 21. coerced sexual activity & $1.13 / 0.51(4.25 / 18.36)$ & 0.91 & 0.91 \\
\hline 23. do/watch sexual things & $1.16 / 0.52(3.42 / 11.72)$ & 0.91 & 0.92 \\
\hline 24. molested & $1.05 / 0.33(7.77 / 63.54)$ & 1.02 & --- \\
\hline 27. sexually abused & $1.04 / 0.27(8.34 / 77.93)$ & 0.78 & 0.73 \\
\hline Emotional neglect $(\mathrm{EN} ; \alpha=0.71)$ & $13.29 / 3.38(0.58 / 0.05)$ & & \\
\hline 5. felt special ${ }^{R}$ & $3.04 / 1.20(-0.55 /-1.08)$ & 0.47 & 0.47 \\
\hline 7. felt loved ${ }^{\mathrm{R}}$ & $2.20 / 0.83(-1.11 / 1.94)$ & 0.64 & 0.64 \\
\hline 13. looked out for ${ }^{R}$ & $2.72 / 0.99(-0.77 /-0.14)$ & 0.79 & 0.78 \\
\hline 19. close family ${ }^{\mathrm{R}}$ & $2.72 / 0.98(-0.68 /-0.07)$ & 0.75 & 0.75 \\
\hline 28. strength and support ${ }^{\mathrm{R}}$ & $2.61 / 0.93(0.93 / 0.44)$ & 0.72 & 0.72 \\
\hline Physical neglect $(\mathrm{PN} ; \alpha=0.57)$ & $11.04 / 2.93(0.58 /-0.07)$ & & \\
\hline
\end{tabular}




\begin{tabular}{|c|c|c|c|}
\hline 1. enough to eat & $2.43 / 1.12(0.20 /-1.00)$ & 0.55 & 0.55 \\
\hline 2. felt protected ${ }^{\mathrm{R}}$ & $2.36 / 0.86(1.38 / 1.98)$ & 0.56 & 0.56 \\
\hline 4. parents drunk/high & $1.41 / 0.85(2.21 / 4.07)$ & 0.36 & 0.37 \\
\hline 6. dirty clothes & $2.58 / 1.04(0.07 /-1.00)$ & 0.41 & 0.41 \\
\hline 26. taken to doctor ${ }^{\mathrm{R}}$ & $3.74 / 0.95(-1.21 / 1.57)$ & 0.74 & 0.74 \\
\hline
\end{tabular}

Note: Superscript R = reverse scored items. Superscript $\uparrow$ depicts that mean scores/SD/skewness/kurtosis and cronbach alpha is based on 4-items. 
Table 2

Factor Correlation Between Latent Factors of Abuse and Neglect in the Modified Model of the CTQ

\begin{tabular}{lllll}
\hline Type of & PA & SA & EN & PN
\end{tabular}
abuse/neglect

\begin{tabular}{|c|c|c|c|c|}
\hline $\mathrm{EA}$ & $0.83 * * *$ & $0.59 * * *$ & $0.74 * * *$ & $0.66 * * *$ \\
\hline PA & & $0.34 * * *$ & $0.57 * * *$ & $0.56 * * *$ \\
\hline $\mathrm{SA}^{\dagger}$ & & & $0.32 * * *$ & $0.30 * *$ \\
\hline $\mathrm{EN}$ & & & & $0.79 * * *$ \\
\hline
\end{tabular}

Note $:$ EA $=$ Emotional abuse. $\mathrm{PA}=$ Physical abuse. $\mathrm{SA}=$ Sexual abuse. $\mathrm{EN}=$ Emotional neglect. $\mathrm{PN}=$ Physical neglect. Superscript $\uparrow$ depicts that the latent factor of sexual abuse comprised of four items.

$* * p<0.01$

$* * * p<0.001$ 
Table 3

Unstandardized Regression Coefficients of the Five Types of Childhood Abuse and Neglect on Gender in a MIMIC Model

\begin{tabular}{lcccc}
\hline $\begin{array}{l}\text { Latent factors } \\
\text { of the CTQ }\end{array}$ & Estimates $(B)$ & S.E. & $z$-test & Direction \\
& & & & of the \\
& & & & -1.39 \\
EA & 0.35 & 0.26 & $2.04 *$ & $\mathrm{M}>\mathrm{F}$ \\
PA & -0.32 & 0.12 & 1.16 & --- \\
SA & 0.11 & 0.09 & 1.27 & --- \\
EN & -0.16 & 0.12 & 0.23 & --- \\
PN & 0.02 & 0.09 & & \\
\hline
\end{tabular}

Note $:$ EA = Emotional abuse. $\mathrm{PA}=$ Physical abuse. $\mathrm{SA}=$ Sexual abuse. $\mathrm{EN}=$ Emotional neglect. $\mathrm{PN}=$ Physical neglect. ${ }^{*} p<0.05$ 
Table 4

Differences Across Number of Maltreatment Types on Depression and PTSD Symptoms, and Pairwise Comparisons Among Youth

From Burundi

\begin{tabular}{|c|c|c|c|c|c|c|}
\hline \multirow[t]{3}{*}{ Variables } & \multicolumn{5}{|c|}{ Number of maltreatment types experienced } & \multirow{3}{*}{$\begin{array}{c}\text { Direction of } \\
\text { the effect }\end{array}$} \\
\hline & One & Two & Three & Four & Five & \\
\hline & \multicolumn{5}{|c|}{ Mean $(S D)$} & \\
\hline Depression & $3.50(2.52)$ & $4.45(3.49)$ & $6.11(3.87)$ & $10.35(5.32)$ & $13.94(5.93)$ & $5>4>3,2,1$ \\
\hline PTSD & $6.50(3.42)$ & $5.61(5.62)$ & $6.12(4.40)$ & $12.10(7.36)$ & $15.40(7.41)$ & $\begin{array}{l}5>3,2,1 \\
4>3,2\end{array}$ \\
\hline
\end{tabular}

Note: Bonferroni's correction term $(p<0.05)$ was used in the pairwise comparisons. 